Gwyneth Sutherlin:

\title{
The Digital Battlefield: Controlling the Technology of Revolution
}

\begin{abstract}
:
Recent conflicts and revolutions have foregrounded a new battlefield where information and communication technology (ICT) will play a crucial role. The producers of ICT frequently use it as a tool for defining and implementing strategies aimed at achieving stability and democracy. While the traditional battlefields remain in upheaval, manoeuvres on the digital terrain do not progress in parallel. This paper will examine the foreign policy implications of the pervasive cultural bias of the ICTs connected to revolution and stabilization efforts describing how this bias shifts power away from the populations using the technology and toward the actors controlling the programs and codes. The ICTs deployed for conflict management and democratization are plagued by cultural bias which disenfranchises users, thereby diminishing the technology's potential for use in participatory actions by removing authorship and contributing to information gatekeeping by the creators of the technology which tend to be European or American.
\end{abstract}

\section{Agenda:}

Introduction

Two Theories of Power

Defining Bias in ICT

The User Experience

Producer Culture

Conclusion

\section{Author:}

Gwyneth Sutherlin:

- University of Bradford, Department of Peace Studies, Bradford, West Yorkshire, BD7 1DP, UK

- $\quad$ 甶 +44 01274 235235, $₫$ g.b.sutherlin@student.bradford.ac.uk

- Relevant Publications:

A Voice in the Crowd: Broader Implications for Crowdsourcing Translation during Crisis. Journal of Information Science. (Forthcoming) 


\section{Introduction}

The debate surrounding the use of ICT to empower democratization efforts and human rights work focuses on the idea of openness. As an extension of the freedom of expression which is vital in a democracy and protected in the UN charter, if individuals are free to convey the details of these events through online platforms then democracy will prevail. Therefore, when developing policies aimed at promoting democracy, access to mobile and online information sharing is a focus, and participation in the information sharing architecture is the goal. Current policies encourage a definition of freedom that equates participation with open access and despotism with censorship and information barriers. This analysis will consider other dimensions to participation such as control of access and format of participation.

ICT has evolved rapidly and emerged from primarily U.S. and western EU cultures; however, the regions where it is applied for democratization efforts differ tremendously by language and culture. Although being concerned with the application of ICT for democratization and conflict management, the expectations, intentions, and goals of the producers of the technology and its users will be explored in a broader theoretical framework in order to contextualize the concept and role of cultural bias. Critical theory and geosemiotics will be used to answer questions such as 'how does bias manifest?' and 'why does it persist?' Finally, recent events will illustrate these theories in action.

\section{Two Theories of Power}

Jürgen Habermas and Michel Foucault's work on discourse and language brings together ideas about information and power. While these intellectual rivals challenged each other's theories, in the context of information and communication technology applied in conflict management, their work describes complementary aspects of power dynamics. For example, the producers of the technology and its users are not participants in the same discourse just as a 6-year-old student and the head of the ministry of education are not. The student's role is to learn and the minister's role is to define how learning happens in this system. Each of these philosophers developed and revised their work over decades, and this article does not intend to engage with their work in depth, yet drawing briefly from Habermas and Foucault provides a useful starting point to frame the perpetuation of cultural bias in ICT.

In Information Science, Stahl ${ }^{1}$ observes that the Habermasian view is attractive to researchers of democracy and human rights because of its normative directions which encourage fair and open dialogue, but cautions there is no space to address hidden inequalities in the system. Stahl continues by summarizing that Foucault's work offers no solutions; the focus on power disparities (such as sane/insane) provides a path to exploring identity-based power relations. Stahl's cursory treatment of arguably dense material is not uncommon in connection to ICT. As the following sections delineate, the kernels of Habermas's theory appear again and again, diluted to popular notions of democracy by the proponents of open access. In particular, the tantalizing parallel between the internet's democratizing potential and a conception of Habermas's ideal speech situation ${ }^{2}$ where universal participation leads to consensus and action.

Foucault articulates power dynamics in more granular shades. ${ }^{3}$ Particularly with regard to imposed identity, this dimension is exposed through Foucault's framework and invisible in Habermas's because the latter does not give it space in rational discourse. Foucault's lens permits the diagnosis of imperfections; only through this lens do problems such as cultural bias become apparent. And it is perhaps because of the union of political rationality

1 Stahl, Bernd: Whose Discourse? A Comparison of the Foucauldian and Habermasian Concepts of Discourse in Critical IS Research.

2 Habermas, Jürgen: Moral Consciousness and Communicative Action.

3 Foucault, Michel: The subject and power. 
in the social sciences and positivism in engineering science that the current discussion is defined by Habermasian notions of participation. Habermas suggests the solution, the ideal toward which we should work. However, his solution insists on certain parameters which must be met in order to achieve equal and universal participation. Proponents of the Habermasian view assert that if barriers to access are removed, then open discourse will proceed. The barriers which are in fact preventing full participation and negotiation of validity among participants are not elements which can be adequately addressed in his framework because they emerged from discourse situations which do not adhere to his parameters. The barrier comes in the form of a biased means of conveyance, the technology, which places limits on the discourse so that validity and consensus can never be reached.

Foucault's work introduces the concept of the mode of power working through dichotomies of identity. These determine an individual's level of participation in the discourse (such as sane and insane). ${ }^{4}$ The dominant group exerts power through naming, through language. In this paper it is extended to users of ICT. Currently, if someone cannot use ICT, s/he would probably be considered illiterate or poor, on the wrong side of the digital divide. ${ }^{5}$ This paper asserts an alternative dichotomy-- users who find themselves cognitively at home in the ICT space and those who enter a cognitively foreign space. More concisely, there is a cognitive in-group and an out-group defined by the mode of power-information control. Pavlenko defines the term 'cognition' as referring to,

"a variety of phenomena which include but are not limited to perception, attention, categorization, inference, reasoning, and socio- cultural belief systems. "6

The cognitive in-group sets the terms of how participants enter the discourse in the Habermasian sense, and therefore how the information we share is represented and codified. Frequently, this group siphons information away from the original authors in a new and homogenized form which fits the prescribed, in-group mode of discourse communication.

\section{Defining Bias in ICT}

Friedman and Nissenbaum began by defining bias in,

"computer systems that systematically and unfairly discriminate against certain individuals or groups of individuals in favor of others. A system discriminates unfairly if it denies an opportunity or a good or it assigns an undesirable outcome... on grounds that are unreasonable or inappropriate."7

ICTs provide users with an opportunity for self-expression, information storing, and engagement with the knowledge economy. Friedman and Nissenbaum further categorize three types of bias: pre-existing, technical, and emergent. ${ }^{8}$

Emergent bias becomes apparent through use because new knowledge, context, or other unanticipated elements enter the system. In this paper, it is hypothesized that significant divergence from the original design intentions leads to emergent bias. Tools that were designed to organize information, share stories, chronicle events in one culture may impede the ideal speech situation in another because the ICT tool imposes an emergent bias. To return to Foucauldian dichotomies, the cognitive in-group and out-groups may not share a common conception of how to input data, or even which data to record. As producer nations export ICTs, they

4 ibid.

5 Graham, Mark: Time Machines and Virtual Portals: The Spatialities of the Digital Divide.

6 Pavlenko, Aneta: Eyewitness Memory in Late Bilinguals: Evidence for Discursive Relativity. 259

7 Friedman, Batya and Nissenbaum, Helen: Bias in Computer Systems. 23

8 ibid pp.24-28 
have consciously exported along with it particular models for informational control. ${ }^{9}$ Friedman and Nissenbaum explain the mechanism of control in terms of bias,

"In this manner, centralized computing systems with widespread use can hold users hostage to whatever biases are embedded within the system." 10

There are nearly 7000 living languages. In the Niger-Congo language family alone, there are 1500 compared to the family to which English belongs which has only $430 .{ }^{11}$ The most diverse language family is also one of the most under-represented on the internet. ${ }^{12}$ Research continues to concentrate on written support for accessibility such as keyboards and coding, as well as breaking barriers to internet access itself, ${ }^{13}$ all fundamentally Habermasian approaches focusing on universal participation. However, without consideration of cultural elements beyond language, the nature of the barrier is invisible. Among 7000 languages, methods for making sense of our world vary enormously. Some cultures have done without nouns or numbers, have a non-linear sense of time, ${ }^{14}{ }^{15}$ have categories of words that most European languages have no concept for including smell and sound, not to mention differences such as orality. ${ }^{16}$ Cognitive psychology and language studies which inform ICT development have come from a small sample, 30 and at most 300, of usually related languages. ${ }^{17}$ The variation of expression among 7000 languages far exceeds the capacity of a single language's prescribed boxes, bars, and scrolling mechanisms in a virtual interface to encapsulate the intended communication of all the rest.

The screen of the computer or mobile device which sets the parameters for how communication can proceed or the way information will be managed assumes the spatial meanings associated with the culture in which it was designed. According to the theory of geosemiotics by Scollon and Wong Scollon, ${ }^{18}$ meaning-making occurs through active engagement between ourselves and the world. It is a dynamic process simultaneously negotiated as we act and react to the material spaces we encounter. The mono-cultural roots of current interface design elements and their arrangement (e.g. timelines, category selection boxes, maps) can be traced with geosemiotics. ${ }^{19}$

ICT cannot be used as an effective or trusted tool if it removes authorship by dissolving intentionality, context, or essential cultural communication elements. Returning to the framework of Habermas and Foucault, the participation is not determined simply by access to the discussion space, but also access to defining the form that participation takes. Makoni and Meinhof emphasize that,

"the real power of the west is not located in its economic muscle and technological might. Rather, it resides in its power to define. "20

9 Burk, Dan: Privacy and Property in the Global Datasphere. 1

10 Friedman, Batya and Nissenbaum, Helen: Bias in Computer Systems. 31

11 Lewis, M. Paul: Ethnologue: Statistical Summaries.

12 Paolillo, John; Pimienta, Daniel; Prado, Daniel: Measuring Linguistic Diversity on the Internet.

13 Olúbòdé-Sàwe, Fúnmi: Digital Communication in Indigenous Languages.

14 Holtzman, Jon: The Local in the Local: Models of Time and Space in Samburu District, Northern Kenya.

15 Mbiti, John: African Religions \& Philosophy.

16 Ong, Walter: Orality and Literacy: the Technologizing of the Word.

17 Evans, Nicholas and Levinson, Stephen: The Myth of Language Universals: Language Diversity and Its Importance for Cognitive Science. 6-7

18 Scollon, Ron and Wong Scollon, Suzie: Discourses in Place: Language in the Material World.

19 ibid.

20 Makoni, Sinfree and Meinhof, Ulrike: Western Perspectives in Applied Linguistics in Africa. 2 
By defining how we communicate and collect information, the west has created a form of colonialism. ${ }^{21} 22$

\section{The User Experience}

For societies working to rebuild civil and governmental structures, post-conflict, expressing and exploring identity is vital. This action is now melded with technology. In interviews from a 2011 Arab bloggers meeting in Tunisia, respondents commenting on the use of ICT emphasized their desire to convey their reality, their 'onthe-ground' perspective. ${ }^{23}$ They were communicating an identity. This sentiment was also expressed in a BBC interview with a Libyan man who shared,

"We've been fighting for our identity for so many years, as well as to know who we are, to tell people who we are. ${ }^{124}$

Identity may be the most vulnerable commodity as mono-cultural technology takes hold in the newest online communities. Statistics from the International Telecommunications Union show a dramatic increase of mobile web browsing from January 2011 to January 2012 in Africa with a jump from 6.33\% to 19.17\%. This rise surpasses Asia at $14.32 \%$, which includes China, the country that has more mobile phone users than the population of Spain. Another important indicator is the predicted 3G coverage increase in the Middle East/Africa region from $7 \%$ in 2009 to $35 \%$ in 2014 . This increase is the largest among the developing regions. For comparison, Western Europe is estimated to grow from 39\% to $92 \%$ and Eastern Europe from $9 \%$ to $40 \%$. ${ }^{25}$ To maintain lines of communication and transaction with economic partners, projects cannot go forward without bolstering connectivity.

\section{Producer Culture}

This seamless transition from economic statistics to the natural conclusion that the internet is a tool of democracy hinges on the two meanings of free-- Water freely flows down a river; People freely express themselves in a democracy. Equating the protection of the free flow of information with the protection of oppressed populations in places such as Iran ${ }^{26}$, is a ruse by technology producing cultures, a play to the public's fear.

The OECD adopted policy guidelines while the White House crafted the International Strategy for Cyberspace beginning with the subtitle 'Prosperity, Security and Openness in Networked World.' ${ }^{27}$ Influenced by these actions, the EU drafted its Cyber Security Directive. ${ }^{28}$ Within these documents, the priority and bulk of language is economic. Freedom from tyranny is not the reason for forming a triangle between the military, civil service, and police on an international scale. Protecting democratic freedom is auxiliary, a rhetorical veil for press releases. These policies are not about human rights; they are about shielding corporations from liability and regulating just enough to protect intellectual property rights as prescribed by the U.S.. Language such as, "the

21 Ess, Charles and Sudweeks, Fay: On the Edge: Cultural Barriers and Catalysts to IT Diffusion among Remote and Marginalized Communities. 3

22 Paolillo, John; Pimienta, Daniel; Prado, Daniel: Measuring Linguistic Diversity on the Internet.

23 BBC Radio 5 Outriders: Arabic Bloggers Meeting, Outriders.

24 Head, Jonathan: Search for Libyan Political Identity.

25 mobiThinking: Global Mobile Statistics 2012.

26 Kornbluh, Karen and Weitzner, Daniel: Foreign Policy of the Internet.

27 Hathaway, Melissa: Securing Our Digital Future.

28 BBC News: UK Decides to Opt in to EU-wide Cyber Security. 
internet is at risk," 29 "looming threat," 30 and "naked power grab led by Russia and China" 31 are misdirection. The real threats that concern technology producers are competition for dominance, sustainable intranets, or limitations on interoperability by countries designing for domestic users. How would it affect intelligence gathering or targeted marketing if a region chose another technology platform, or if it stagnated post-conflict failing to contribute streams of data to the web? If countries remain 'data silent' or connect to the internet in a less accessible manner, it would be disadvantageous to western political and economic interests.

Returning to the two meanings of 'free,' when the organization responsible for protecting human rights (UN$\mathrm{HRC}$ ) recommended creating more coherent international norms to ensure freedom of expression on the internet, the response by lawmakers in the U.S. was indignation that there might be limitations imposed on the internet. ${ }^{32}$ Here the two meanings of 'free' diverge. The UN recommended continuing to protect the same freedom of expression that is guaranteed in article 19 of the Universal Declaration of Human Rights (presciently described as 'any media') on the internet. ${ }^{33}$ The American technology producers aimed to protect the free flow of information, the source of economic power, from regulation. If these two things were truly equivalent, they would be in agreement.

\section{The Technology of Revolution}

In the $21^{\text {st }}$ century, material support for pro-democracy activists includes empowering them with the technology for change. The U.S. State Department has begun an initiative called TechCamp. ${ }^{34}$ Indonesia was selected as one program site, not because of its socio-political challenges or potential diplomatic partnership with the U.S., but because,

"it ha[d] the second largest number of Facebook members, after the United States. This strong social media understanding gives a stronger platform for innovation in mobile and web applications. Several corporate partners have signed on.... ${ }^{35}$

Rather than developing tools that meet the needs of the population, the camp fostered an expansion of U.S. style technology platforms, extending the market base in a critical region between India and China. With this move, the cognitive in-group could facilitate a large populations' participation in the dominant discourse space while maneuvering to inhibit alternative modes of discourse in another example of U.S. technology displacing indigenous systems. It is this type of installed technology that is lauded as innovative when it is regurgitated by local developers. ${ }^{37}$ Praise for democracy in action may in fact be praise for a battlefield victory, an expansion of U.S.-style technology.

The Africa4All Parliamentary Initiative was developed in partnership between five participating African nations and the European Gov2U non-profit organization. ${ }^{38}{ }^{39}$ Its aim is delivering open, democratic dialogue with universal participation through the help of ICT tools. By relying on the Habermasian concept of democracy, the

29 Kornbluh, Karen and Weitzner, Daniel: Foreign Policy of the Internet.

30 Krigman, Eliza: Concerns Spread as U.N. Poises for Internet Regulation.

31 ibid.

32 ibid.

33 UN: United Nations Webcast - Panel on Right to Freedom of Expression.

34 U.S. Department of State: eDiplomacy \& Innovation Teams Bring Together Technologists, Civil Society and Private Sector.

35 ibid.

36 Burk, Dan: Privacy and Property in the Global Datasphere.

37 The Stream

38 Africa4All: http://www.africa4all.net/index.php

39 Gov2U: http://www.gov2u.org/index.php/who-we-are 
barriers to participation such as the discourse platform itself, may not be apparent. In this project, action area categories, survey formats, and text-based communication persist in the manner of the cognitive in-group. Beyond language access, this e-governance ICT application remains incongruous to context and user communication preferences.

During a 2011 interview, The Register maintained,

"The best defense is, apparently, not to speak English, as the language barrier can give local content providers the vital advantage they need before Google et al take over, ${ }^{\prime 40}$

a sentiment expressed by the Secretary General of the International Telecommunications Union, Dr. Hamadoun Touré. This is the sort of strategy actors must engage in in order to shift power between cognitive in-groups and out-groups; battlefield victories are determined by information control, the economic and political advantage.

\section{Conclusion}

Through gatekeeping, controlling information and communication data, European and American actors seek to determine the boundaries of the new digital battlefield. Couched in the language of Habermas, frontiers are defined in terms of the struggle between democratic freedom and autocratic censorship; recasting the scene as one between producers and users, the power dynamics resemble a more Foucauldian dichotomy in which the dominant group, the producers, determines interaction in political discourse. In the $21^{\text {st }}$ century, the dichotomy is one referred to as the digital divide. It is the supposition of this paper that this dichotomy is, in fact, between a cognitive in-group and out-group based around cognitive dimensions distinctive to each culture. Current ICT interface design exhibits cognitive elements that reflect American and European cultural norms. With the spread of the internet and ICT, only language has been seen as a barrier to participation and has therefore been the focus of research and policy initiatives. This approach assumes a universal user. However, language is only one element of the cognitive experience; the universal user does not exist. The in-group/outgroup dichotomy persists through the cultural bias imposed by the producer culture to protect the form and flow of information. By applying this neo-colonial strategy to information gathering, European and American producer cultures are not simply positioning themselves on the new battlefield to the best advantage, they are determining the shape of the field by commanding the programs and codes through which the information flows.

\section{References}

Africa4All: [online] http://www. africa4all.net/index.php [Accessed 20 April 2011].

BBC News: UK decides to opt in to EU-wide cyber security plan. 2012. [online] http://www.bbc.co.uk/news/uk-politics-12354931 [Accessed 29 April 2012].

BBC Radio 5 Outriders: Arabic Bloggers Meeting. Outriders 2011. [podcast] http://downloads.bbc.co.uk/podcasts/fivelive/pods/pods20111011-1600a.mp3 [Accessed 27 October 2011].

Burk, Dan: Privacy and property in the global datasphere. Minnesota Legal Studies Research Paper No 05-17, 2005.

Ess, Charles and Sudweeks, Fay: On the Edge: Cultural Barriers and Catalysts to IT Diffusion among Remote and Marginalized Communities. New Media Society. 2001 (3) 259. [online] http://nms.sagepub.com/content/3/3/259 [Accessed 15 September 2011]. 
Evans, Nicholas and Levinson, Stephen: The myth of language universals: Language diversity and its importance for cognitive science. Behavioral and Brain Sciences, 2009. [online] http://journals.cambridge. org/production/action/cjoGetFulltext?fulltextid=6426828 [Accessed 11 January 2012].

Foucault, Michel: The subject and power. Critical Inquiry 1982 (8) (4) 777-795. [online] http://Www.jstor.org/stable/1343197 [Accessed 11 January 2012].

Friedman, Batya and Nissenbaum, Helen: Bias in Computer Systems. In: B. Friedman, ed. Human values and the design of computer technology. Cambridge, Cambridge University Press 1997. 21-40

Gov2U: [online] http://www.gov2u.org/index.php/who-we-are [Accessed 20 April 2011].

Graham, Mark: Time Machines and Virtual Portals: The Spatialities of the Digital Divide. Progress in Development Studies 2011 (11) (3) 211-227. [online] DOI: 10.1177/146499341001100303 [Accessed 21 November 2012].

Habermas, Jürgen: Moral consciousness and communicative action. Cambridge, Polity Press 1990.

Hathaway, Melissa: Securing our digital future. The White House Blog 2009. [online] http://www. whitehouse.gov/cyberreview [Accessed 20 February 2012].

Head, Jonathan: Search for Libyan political identity. BBC The World Today 17 February, 2012. [podcast] http://www.bbc.co.uk/programmes/p00nnkr8\#synopsis. [Accessed 17 February 2012].

Holtzman, Jon: The Local in the Local: Models of Time and Space in Samburu District, Northern Kenya. Current Anthropology 2003 (45) 61-84. [online] http://www.jstor.org/stable/10.1086/379635 [Accessed 10 May 2012].

Kornbluh, Karen and Weitzner, Daniel: Foreign policy of the internet. U.S. Department of State 2011. [online] http://www.state.gov/e/eb/rls/rm/2011/168612. htm [Accessed 17 February 2012].

Krigman, Eliza: Concerns spread as U.N. poises for internet regulation. POLITICO 2012. [online] http://www.politico.com/news/stories/0412/74844.html [Accessed 5 April 2012].

Lewis, M. Paul: Ethnologue: statistical summaries, 16th ed. 2009. [online] http://www.ethnologue.com/ethno_docs/distribution.asp?by=family [Accessed 20 December 2011].

Makoni, Sinfree and Meinhof, Ulrike: Western perspectives in applied linguistics in Africa. AILA Review 2004 (17) (1) 77-104. [online] DOI: 10.1075/aila.17.09mak [Accessed 28 March 2012].

Mbiti, John: African Religions \& Philosophy. $2^{\text {nd }}$ ed. Oxford, Heinemann 1990.

mobiThinking: Global mobile statistics 2012. [online] http://mobithinking.com/mobile-marketing-tools/latestmobile-stats\#mobilebroadband [Accessed 28 February 2012].

Olúbòdé-Sàwe, Fúnmi: Digital communication in indigenous languages. In:Taiwo, O.A. ed. Handbook of research on discourse behavior and digital communication : language structures and social interaction. 2010. 564 [online] ebook ISBN: 9781615207732 [Accessed 20 January 2012].

Ong, Walter: Orality and Literacy: the technologizing of the word. New York, Routledge 1982.

Paolillo, John; Pimienta, Daniel; and Prado, Daniel: Measuring linguistic diversity on the Internet. United Nations Educational,Scientific and Cultural Organization 2005. [online] http://unesdoc. unesco.org/images/0014/001421/142186e. PDF [Accessed 20 August 2011].

Pavlenko, Aneta: Eyewitness memory in late bilinguals: Evidence for discursive relativity. International Journal of Bilingualism 2003 (7) 257-281. [online] DOI: 10.1177/13670069030070030301 [Accessed 24 March 2012].

Ray, Bill: ITU Gen Sec: Why not speaking English can be a virtue. The Register, 2011. [online] http://www. theregister.co.uk/2011/06/24/itu gen sec/ [Accessed 25 January 2012].

Scollon, Ron and Wong Scollon, Suzie: Discourses in place : language in the material world. London, Routledge 2003.

Stahl, Bernd: Whose Discourse? A comparison of the Foucauldian and Habermasian concepts of discourse in critical IS research. New York, Proceedings of the Tenth Americas Conference on Information Systems 2004. [online] www.cse.dmu.ac.uk/ bstahl/publications/2004 Foucault Habermas AMCIS.pdf [Accessed 27 October 2011]. 
Al Jazeera English: The Stream. African Innovations 2011. [podcast] http://stream.aljazeera.com/story/african-innovations-0022111 [Accessed 23 March 2012].

UN: United Nations Webcast: Panel on Right to Freedom of Expression, 19th Session Human Rights Council. [webcast] [Accessed 14 March 2012].

U.S. Department of State: eDiplomacy \& Innovation Teams Bring Together Technologists, Civil Society and Private Sector. 2011. [online] http://www.state.gov/r/pa/prs/ps/2011/05/163321. htm [Accessed 26 October 2011]. 